\title{
Influence of peptidylarginine deiminase type 4 genotype and shared epitope on clinical characteristics and autoantibody profile of rheumatoid arthritis
}

\author{
B Hoppe, ${ }^{1}$ T Häupl, ${ }^{2}$ K Egerer, ${ }^{2}$ R Gruber, ${ }^{3}$ H Kiesewetter, ${ }^{2}$ A Salama, ${ }^{2}$ G R Burmester, ${ }^{2}$ \\ T Dörner
}

${ }^{1}$ Berthold Hoppe, Central Institute of Laboratory Medicine and Pathobiochemistry, Charité

- Universitätsmedizin Berlin, Campus Virchow-Klinikum, Augustenburger Platz 1, 13353 Berlin, Germany; ${ }^{2}$ Charité Universitätsmedizin Berlin, Berlin, Germany; ${ }^{3}$ LudwigMaximilians-Universität, München, Germany

Correspondence to: Dr B Hoppe, Central Institute of Laboratory Medicine and Pathobiochemistry, Charité Universitätsmedizin Berlin, Campus Virchow-Klinikum, Augustenburger Platz 1, 13353 Berlin, Germany; berthold. hoppe@charite.de

Accepted 9 July 2008 Published Online First 16 July 2008

\section{ABSTRACT}

Background: Recent evidence suggests that distinction of subsets of rheumatoid arthritis (RA) depending on anticyclic citrullinated peptide antibody (anti-CCP) status may be helpful in distinguishing distinct aetiopathologies and in predicting the course of disease. HLA-DRB1 shared epitope (SE) and peptidylarginine deiminase type 4 (PADI4) genotype, both of which have been implicated in anti-CCP generation, are assumed to be associated with RA.

Objectives: To elucidate whether PADI4 affects the clinical characteristics of RA, and whether it would modulate the effect of anti-CCPs on clinical course. The combined effect of SE and PADI4 on autoantibody profile was also analysed.

Methods: 373 patients with RA were studied. SE, padi4 94C $>$ T, rheumatoid factor, anti-CCPs and antinuclear antibodies (ANAs) were determined. Disease severity was characterised by cumulative therapy intensity classified into ordinal categories (CTI-1 to CTI-3) and by Steinbrocker score.

Results: CTI was significantly associated with disease duration, erosive disease, disease activity score (DAS) 28 and anti-CCPs. The association of anti-CCPs with CTI was considerably influenced by padi4_94C $>$ T genotype $(C / C$ : $\mathrm{OR}_{\mathrm{adj}}=0.93, \mathrm{p}_{\mathrm{adj}}=0.92 ; \mathrm{C} / \mathrm{T}: \overline{\mathrm{OR}}_{\mathrm{adj}}=2.92$,

$\mathrm{p}_{\mathrm{adj}}=0.093 ; \mathrm{T} / \mathrm{T}: \mathrm{OR}_{\mathrm{adj}}=15.3, \mathrm{p}_{\mathrm{adj}}=0.002$ ). Carriage of padi4_94T exhibited a significant trend towards higher Steinbrocker scores in univariate and multivariate analyses. An association of padi4 94C $>$ T with ANAs was observed, with noteworthy differences depending on SE status (SE-: $\mathrm{OR}_{\mathrm{adj}}=6.20, \mathrm{p}_{\mathrm{adj}}<0.04$; $\mathrm{SE}+$ : $\mathrm{OR}_{\mathrm{adj}}=0.36, \mathrm{p}_{\mathrm{adj}}=0.02$ ) and significant heterogeneity between the two SE strata $(p=0.006)$.

Conclusions: PADI4 genotype in combination with antiCCPs and SE modulates clinical and serological characteristics of RA.

Rheumatoid arthritis (RA) is a common chronic autoimmune disease of unknown aetiology. ${ }^{1} \mathrm{~A}$ central challenge in clinical practice is the identification of patients who need more intensive treatment at an early stage, as many patients develop joint damage during the first few months after disease onset. ${ }^{2}$ Rheumatoid factor (RF) and/ or anti-citrullinated protein antibodies (ACPAs) have been implicated to be associated with more severe joint destruction and a more aggressive disease course. ${ }^{145}$ The major function of HLADRB1 shared epitope (SE) in the pathogenesis of
RA is thought to primarily consist of giving the appropriate immunological context to respond to environmental challenges with production of ACPAs, which themselves influence disease. ${ }^{6-9}$ The association of SE with ACPA-positive RA and its influence on ACPA concentration is well established. ${ }^{5}$ Another genetic trait that presumably influences susceptibility to RA is the peptidylarginine deiminase type 4 (PADI4, MIM: 605347) genotype reflected by padi4_94C > T (rs2240340). ${ }^{10-12}$ PADI4 post-translationally converts peptide-bound arginine residues into citrulline, and this process generates citrullinated epitopes, which are the essential targets of the RA-specific ACPAs. ${ }^{5}$

In this retrospective study, we analysed the association of padi4_94C $>\mathrm{T}$ and anti-citrullinated peptide antibodies (anti-CCPs), a prime example of ACPAs, with disease severity as reflected by cumulative therapy intensity (CTI), which was a priori classified into three ordinal categories. ${ }^{13}$ Erosive joint status assessed by Steinbrocker score was used as an additional indicator of disease severity. To reveal possible modulating properties of the PADI4 genotype on the effect of anti-CCPs on disease severity, we stratified analyses by padi4_94C $>$ T. Finally, we analysed the interactive effect of SE and PADI4 genotype on the autoantibody profile.

\section{METHODS}

\section{Study population and clinical data}

In this study, 373 consecutive patients with RA presenting for regular visits were enrolled from the Department of Rheumatology and Clinical Immunology, Charité Berlin. All patients fulfilled the American College of Rheumatology criteria for the classification of RA. ${ }^{14}$ The patients are under continuous medical attendance in our outpatient unit. Individual therapy courses of all enrolled patients were recorded. The CTI was a priori classified into three ordinal categories (CTI-1: methylprednisone, hydroxychloroquine, sulfasalazine; CTI-2: methotrexate, gold, leflunomide, ciclosporin A, azathioprine; CTI-3: cyclophosphamide, tumour necrosis factor $\alpha$ blockers). Patients were classified on the basis of the antirheumatic drug corresponding to the highest CTI category they had ever received. This classification is a local adaptation of an approach described previously for the assessment of RA severity. ${ }^{13}$ Radiographic data from the time of enrolment were available in 290 
cases. Classification into non-erosive (Steinbrocker score $\leqslant \mathrm{I}$ ) and erosive (Steinbrocker scores II-IV) disease was performed. ${ }^{15}$

The genotype frequencies of padi4_94C $>\mathrm{T}$ in a control group consisting of healthy people and non-RA patients from our geographic region were determined in 282 consecutive caucasian blood donors and 335 consecutive patients with no history of autoimmune diseases presenting at our clinic for thrombophilia work-up. ${ }^{16}$

The study was approved by the local ethics committee. All participants were included in the study after they had provided informed consent.

\section{Autoantibody detection}

Anti-CCP IgG antibodies were quantified in 346 patients at the time of enrolment with a second-generation ELISA using the Immunoscan RA kit (Euro-Diagnostica, Dahlewitz, Germany). A cut-off value of 25 arbitrary units/ml was used.

ANAs were determined in 354 patients using an indirect immunofluorescence assay on HEp-2 cells with an IgG-specific secondary antibody (Generic Assays, Dahlewitz, Germany). Patients with a titre of $\geqslant 320$ were considered ANA positive.

RFs were quantified in 359 patients using an ELISA-based IgM-specific technique and a cut-off value of $24 \mathrm{IU} / \mathrm{ml}$ (DLD Diagnostika, Hamburg, Germany).

\section{Genotyping of PADI4 and SE}

PADI4 genotypes were discriminated for all patients and controls by padi4 94C $>$ T (rs2240340) using allele-specific primer pairs. Specificities of the primer pairs were evaluated on 30 sequenced DNA samples. ${ }^{17} 18$

SE was defined by HLA-DRB1 alleles with the following constellation at the corresponding DR $\beta 1$ chain residues: 67Leu69Glu-71Lys or Arg-74Ala-86Gly or $\mathrm{Val} .{ }^{19} \mathrm{SE}$ status was available for 215 patients with RA and 282 healthy controls. High-resolution HLA-DRB1 typing was performed using standard techniques (Dynal, Oslo, Norway; GenoVision, Vienna, Austria; Protrans, Ketsch, Germany). ${ }^{18}$

Table 1 Characteristics of the study population $(n=373)$

\begin{tabular}{ll}
\hline Characteristic & Patients with RA \\
\hline Age (years) & $51(38-61)$ \\
Female & 76.1 \\
Disease duration (years) & $5(1-11.3)$ \\
Rheumatoid factor ( $\geqslant 25 \mathrm{IU} / \mathrm{ml})$ & 75.8 \\
$\quad$ Titre $(\mathrm{IU} / \mathrm{ml})$ & $97(25-277)$ \\
Anti-CCPs ( $>25 \mathrm{AU} / \mathrm{ml})$ & 61.3 \\
$\quad$ Titre $(\mathrm{AU} / \mathrm{ml})$ & $91(1-568)$ \\
Antinuclear antibodies ( $\geqslant 320)$ & 29.4 \\
$\quad$ Titre & $80(80-320)$ \\
Shared epitope & 49.3 (SE/se), 13.5 (SE/SE) \\
padi4_94C $>$ T & 49.3 (C/T), 19.8 (T/T) \\
Steinbrocker score & $36.2(\leqslant \mathrm{I}), 41.4$ (III), 14.1 (III), 8.3 (IV) \\
Disease activity score 28 & $5.0(4.03-6.19)$ \\
$\quad<3.2$ & 15.7 \\
$3.2-5.1$ & 32.2 \\
$\quad>5.1$ & 52.2 \\
CTI & 38.6 (CTI-1), 46.9 (CTI-2), 14.5 (CTI-3) \\
\hline
\end{tabular}

Values are either percentage or median (interquartile range).

Anti-CCP, anti-cyclic citrullinated peptide; CTI, cumulative therapy intensity; SE/se, 1 copy of shared epitope; SE/SE, 2 copies of shared epitope; C/T, padi4_94C/T (variant heterozygous); T/T, padi4 94T/T (variant homozygous).

\section{Statistical analysis}

For univariate analyses, odds ratios (ORs) and exact 95\% CIs were calculated. For stratified univariate analyses, Breslow and Day's (BD) $\chi^{2}$ test of homogeneity was used to test whether an association differed significantly across the two strata. For calculations on the effect of allele dose of padi4_94C > T or SE genotype, the corresponding wild-type was used as the reference group, and a test for linear trend of the log odds (trend test) was included.

For multivariate analyses, ORs and 95\% CIs were calculated by logistic regression analyses with adjustment for sex, duration of disease, disease activity score (DAS)28 and erosive joint status or CTI. For analyses on autoantibody profile, sex, duration of disease, DAS28, CTI and presence of RFs, antiCCPs and ANAs were included. Depending on the variable used for stratification (SE or padi4_94C $>$ T), the logistic regression model contained padi4 94C $>\mathrm{T}$ or SE genotype, respectively. The Wald test was used to test whether an association differed significantly across the two stratified logistic regression models. The comparisons of autoantibody concentrations between PADI4 and SE genotypes were performed by Mann-Whitney $U$ test or, in the case of testing for allele-dose-dependency, by the Cuzick non-parametric test for trend. All statistical analyses were performed using Stata Statistical Software for Macintosh, release 10.0 .

\section{RESULTS}

\section{Characteristics of the study population}

Table 1 gives the characteristics of the RA population.

The controls consisted of healthy individuals and non-RA patients. In healthy individuals, $62.1 \%$ were carriers of padi4_94T (1 copy, 47.9\%; 2 copies, $14.2 \%$ ). SE was present in $35.8 \%$ of healthy controls ( 1 copy, $28.7 \% ; 2$ copies, $7.1 \%$ ). In the non-RA patients, $61.8 \%$ were carriers of padi4_94T (1 copy, $47.2 \% ; 2$ copies, $14.6 \%$ ). There was no heterogeneity in the distribution of PADI4 genotypes between either part of the control group $(p=0.98)$.

\section{PADI4 genotype and RA}

Carriage of padi4 94T was associated with susceptibility to RA $(\mathrm{OR}=1.38, \mathrm{p}=0.02)$. This association was allele-dose-dependent (trend test, $\mathrm{p}=0.005 ; 1$ copy: $\mathrm{OR}=1.28, \mathrm{p}=0.09 ; 2$ copies: $\mathrm{OR}=1.70, \mathrm{p}=0.006)$. As the padi4_94C $>\mathrm{T}$ genotype distribution in our patients with RA was dependent on CTI and Steinbrocker score, we tested whether association of padi4_94C $>$ T with susceptibility to RA would be restricted to patients with more severe disease. In fact, whereas there were no significant differences in PADI4 genotype distributions in patients with CTI-1 or Steinbrocker scores <II compared with controls (trend test, $p=0.82$ and $p=0.24$, respectively), in patients with higher disease severity, ie, CTI-2/3 (CTI-2/3 versus controls: trend test, $p=0.0003 ; 1$ copy: $\mathrm{OR}=1.47, \mathrm{p}=0.03 ; 2$ copies: $\mathrm{OR}=2.26$, $\mathrm{p}=0.0002$ ) or Steinbrocker score $\geqslant$ II (Steinbrocker score $\geqslant$ II versus controls: trend test, $p=0.0005 ; 1$ copy: $O R=1.29$, $\mathrm{p}=0.20 ; 2$ copies: $\mathrm{OR}=2.34, \mathrm{p}=0.0003$ ), padi4_94C $>\mathrm{T}$ was significantly associated with RA.

\section{Factors influencing CTI}

In univariate and multivariate analyses, duration of disease, presence of erosive disease, anti-CCP status and DAS28 were significantly associated with CTI (CTI-2/3 versus CTI-1) (table 2). An association of padi4_94C $>\mathrm{T}$ carrier status with CTI could be demonstrated only in univariate analysis (table 2). 
Table 2 Factors influencing disease severity as reflected by cumulative therapy intensity (CTI-2/3 versus CTI-1)

\begin{tabular}{lcl}
\hline & OR (p value) & Adjusted OR (p value) \\
\hline Duration of disease (quartiles) $(\mathrm{n}=356)$ & $<10^{-26}$ & $<0.001$ \\
Erosive disease $(\mathrm{n}=290)$ & $4.50\left(<10^{-8}\right)$ & $2.14(0.02)$ \\
$\begin{array}{l}\text { Disease activity score (DAS) } 28 \\
(\mathrm{n}=370)\end{array}$ & $\left(<10^{-5}\right)$ & $(0.003)$ \\
$<3.2(\mathrm{n}=58)$ & 1 (referent) & 1 (referent) \\
$3.2-5.1(\mathrm{n}=119)$ & $0.46(0.05)$ & $0.29(<0.04)$ \\
$>5.1(\mathrm{n}=193)$ & $0.21\left(10^{-5}\right)$ & $0.18(0.003)$ \\
Anti-CCP $(\mathrm{n}=346)$ & $1.69(<0.02)$ & $2.32(<0.02)$ \\
padi4_94C/C $(\mathrm{n}=105)$ & $1.10(0.81)$ & $0.93(0.92)$ \\
padi4_94T $(\mathrm{n}=241)$ & $2.00(0.01)$ & $3.46(0.007)$ \\
padi4_94C $(\mathrm{n}=276)$ & $1.31(0.28)^{*}$ & $1.78(0.18) \dagger$ \\
padi4_94T/T $(\mathrm{n}=70)$ & $5.20(0.002)^{*}$ & $15.3(0.002) \dagger$ \\
padi4_94T $(\mathrm{n}=373)$ & $1.57(<0.05)$ & $1.22(0.57)$ \\
\hline
\end{tabular}

Odds ratios (ORs) and $p$ values of univariate and multivariate analyses (adjusted for sex, age, duration of disease, DAS28 and erosive joint status if applicable) are given. Numbers of patients are indicated.

*BD $\chi^{2}$ test of homogeneity: $p=0.02$

†Wald test: $p<0.02$.

The presence of neither RFs, ANAs nor SEs directly influenced CTI. With respect to the relation between anti-CCPs and CTI, a diverging effect was found after stratification for padi4 $94 \mathrm{C}>\mathrm{T}$, with restriction of the association of anti-CCPs with CTI to the padi4_94T positive stratum $(\mathrm{OR}=2.00, \mathrm{p}=0.01)($ table 2$)$. The difference in the effect of anti-CCPs on CTI between the two padi4_94C $>\mathrm{T}$ strata in univariate analysis did not reach statistical significance (BD $\chi^{2}$ test of homogeneity, $\mathrm{p}=0.21$ ). However, in strata defined by padi4_94C, ie, carriage of at least one padi4_94C (wild-type) allele, and padi4_94T/T (two padi4_94T copies), anti-CCPs were significantly associated with CTI only in the padi4_94T/T stratum $(\mathrm{OR}=5.2, \mathrm{p}=0.002)$ with significant heterogeneity between the two strata ( $\mathrm{BD} \chi^{2}$ test of homogeneity, $p=0.02$ ) (table 2). Logistic regression analyses confirmed that anti-CCPs were independently associated with CTI only in padi4_94T-positive patients (padi4_94T: $\quad \mathrm{OR}_{\mathrm{adj}}=3.46, \quad \mathrm{p}_{\mathrm{adj}}=0.007 ; \quad$ padi4_94T/T: $\mathrm{OR}_{\mathrm{adj}}=15.3$, $\left.\mathrm{p}_{\mathrm{adj}}=0.002\right)$ (table 2).

On comparison of padi4_94T carrier status in all CTI categories, among anti-CCP-positive patients the frequency of padi4_94T carriers increased significantly from $63.0 \%$ in CTI-1 to $73.8 \%$ and $88.9 \%$ for CTI-2 and CTI-3, respectively (trend test, $\mathrm{p}=0.004$; CTI-2: $\mathrm{OR}=1.65, \mathrm{p}=0.13$; CTI-3: $\mathrm{OR}=4.70$, $\mathrm{p}=0.005$ (reference: CTI-1)) (fig 1A). In anti-CCP-negative patients, the frequency of padi4_94T carriers was essentially the same as that of the control group for all CTI categories (CTI-1: 63.5\%; CTI-2: 67.2\%; CTI-3: 61.5\%) (fig 1B).

\section{Factors influencing erosive joint status}

Duration of disease $\left(p<10^{-9}, p_{\text {adj }}<0.0001\right)$ and CTI $(O R=4.50$, $\left.\mathrm{p}<10^{-8} ; \mathrm{OR}_{\mathrm{adj}}=2.05, \mathrm{p}_{\mathrm{adj}}=0.03\right)$ influenced directly erosive joint status (Steinbrocker score $\geqslant$ II) in univariate and multivariate analyses. The presence of neither anti-CCPs $(\mathrm{OR}=1.45$, $p=0.15)$, RFs, ANAs, SE, DAS28, nor padi4_94T were significantly associated with the presence of erosive disease (Steinbrocker score $\geqslant \mathrm{II}$ ). When padi4 94T carrier status was analysed in ordinal categories defined by Steinbrocker scores, a trend towards higher padi4_94T carrier frequencies with increasing Steinbrocker scores could be detected in our study population (trend test, $\mathrm{p}=0.06$ (reference: Steinbrocker score $\leqslant \mathrm{I})$ and $\mathrm{p}<0.004$ (reference: controls)) (fig $2 \mathrm{~A}$ ). When carriage of two padi4_94T copies (padi4_94T/T) was considered, the
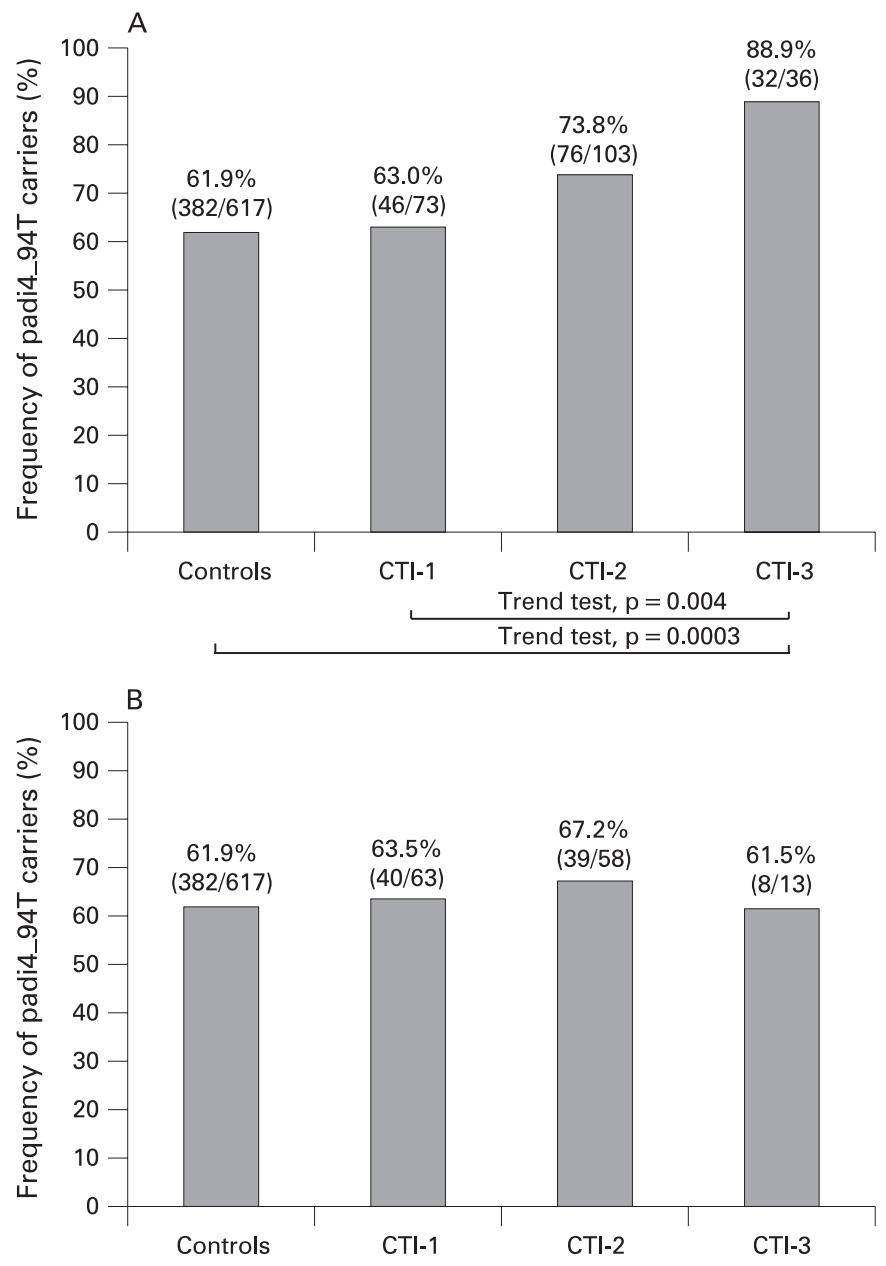

Figure 1 Influence of padi4_94C >T on cumulative therapy intensity (CTI) dependent on the antibody to cyclic citrullinated peptide (anti-CCP) status. Carrier frequencies of padi4_94T in controls and in (A) anti-CCPpositive and (B) anti-CCP-negative patients with rheumatoid arthritis ordinally categorised by CTI (CTI-1 to CTI-3) are shown.

increasing frequency of carriers with increasing Steinbrocker scores was even more pronounced (trend test, $p<0.003$ (reference: Steinbrocker score $\leqslant \mathrm{I}$ ) and $\mathrm{p}<10^{-5}$ (reference: controls)) (fig 2B). After adjustment for possible confounding factors (sex, age, duration of disease, DAS28, CTI, serological status), the trend for higher padi4_94T and padi4_94T/T frequencies with increasing Steinbrocker scores continued to be detectable at comparable statistical significance levels (padi4_94T: $p_{\text {adj }}<0.004$; padi4_94T/T: $p_{\text {adj }}=0.008$ (reference: Steinbrocker score $\leqslant$ I)) (fig 2).

\section{Factors influencing autoantibody profile}

The combined influence of SE and padi4_94C > T on autoantibody profile was analysed in 215 patients, who had been completely characterised for both genotypes. Presence of antiCCPs and the anti-CCP concentration were clearly associated with the presence of SE $(O R=2.93 ; p=0.0002$, Mann-Whitney $U$ test: $p<0.0001$ ) and number of SE alleles (trend test: $p=0.0001$ ). Presence of anti-CCPs was significantly influenced by neither carriage of padi4_94T $(O R=1.43, p=0.13)$ nor padi4_94T allele dose ( 1 copy: $\mathrm{OR}=1.32, \mathrm{p}=0.27 ; 2$ copies: $\mathrm{OR}=1.77, p=0.08$; trend test: $p=0.07$ (reference: padi4_94C/C)). In univariate analyses, no further association between presence of anti-CCPs, RFs or ANAs and a single genotype (SE or 

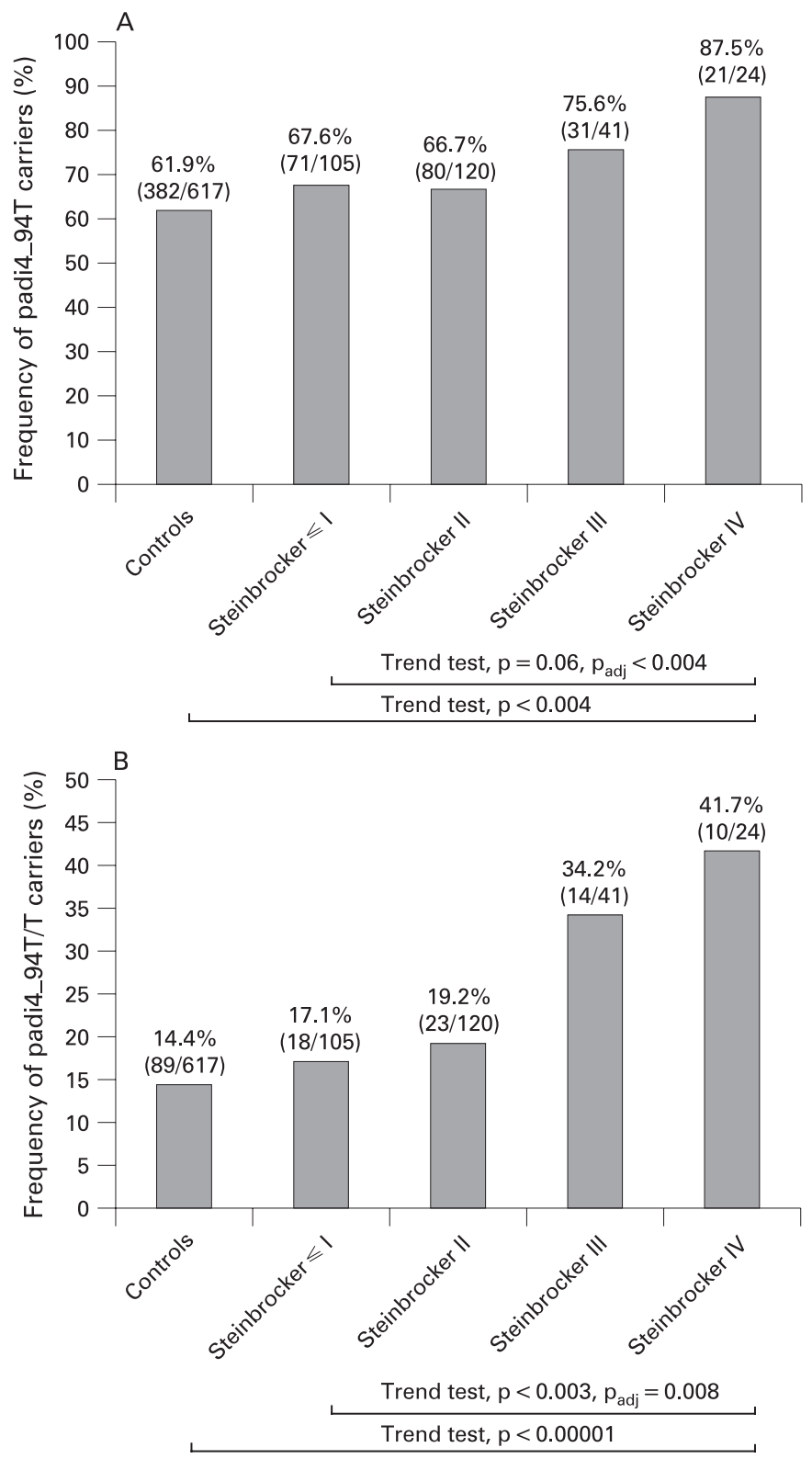

Figure 2 Influence of padi4_94C $>$ T on erosive joint status. Frequencies of carriers of $(A)$ one padi4_94T copy (padi4_94T) and (B) two padi4_94T copies (padi4_94T/T) in controls and patients with RA ordinally categorised by Steinbrocker score ( $\leqslant$ I, II, III, IV) are shown. For analyses based on Steinbrocker score $\leqslant I$ as reference group $p$ values after adjustment for sex, age, duration of disease, disease activity score 28 , cumulative therapy intensity and serological status are given.

padi4_94C > T) could be identified. However, after stratification for $\mathrm{SE}$, the influence of padi4 $94 \mathrm{C}>\mathrm{T}$ genotype on autoantibody profile was notable (fig 3 ). In univariate and multivariate analyses, significant heterogeneity existed between SE-positive and SEnegative patients with respect to association of padi4_94C $>\mathrm{T}$ genotype with ANAs (test of homogeneity, $p<0.01$ and $p_{a d j}=0.006$, respectively), with positive association in the SEnegative stratum and negative association in the SE-positive stratum (table 3).

The same phenomenon was observed when padi4_94T allele dose was considered. In SE-positive patients, the number of padi4_94T alleles was negatively associated with ANAs (trend test, $\mathrm{p}<0.02$ ), and in SE-negative patients there was a positive association (trend test, $\mathrm{p}<0.03$ ) when padi4_94C/C was used as

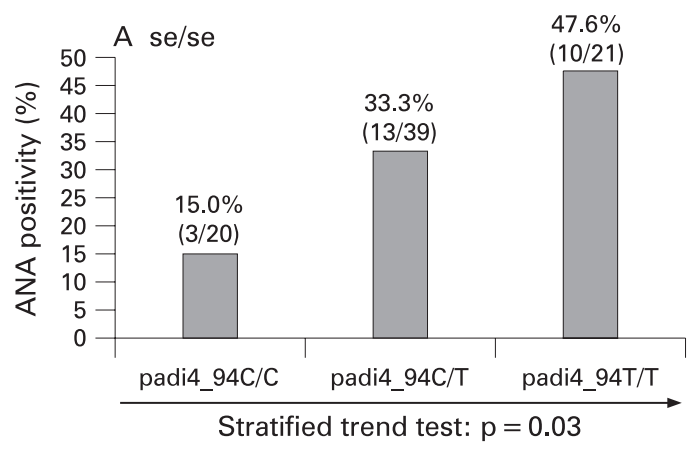

B SE

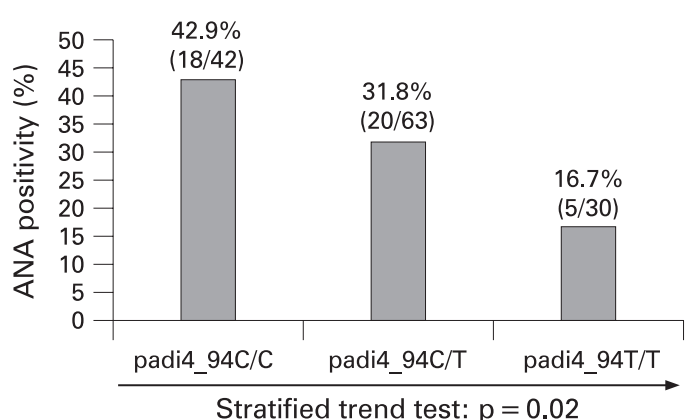

Figure 3 Presence of antinuclear antibodies (ANAs) is interactively dependent on padi4_94C > T genotype and shared epitope. Frequencies of ANA-positive (titre $\geqslant 320$ ) patients with RA in dependency on padi4_94C > T genotype and presence (SE) or absence (se/se) of shared epitope are given. There was significant $(p=0.001)$ heterogeneity between the two strata with respect to the relation between padi4_94C > T and ANA positivity.

the reference group (fig 3). The heterogeneity of this allele-dosedependent effect between the two SE strata was highly significant in univariate $(p=0.001)$ and multivariate $\left(p_{\text {adj }}=0.0002\right)$ analyses (table 3$)$.

\section{DISCUSSION}

The results of this study suggest that the PADI4 genotype critically modulates the effect of anti-CCPs on clinical characteristics of RA. The PADI4 genotype itself appears to influence joint destruction. Interactively, PADI4 genotype and $\mathrm{SE}$ influence the autoantibody profile of RA. Hence, it could be hypothesised that information on the two genetic traits characterise different RA subsets with distinct aetiopathogeneses. Finally, an association of padi4_94C > T with susceptibility for RA was confirmed, and, on the basis of the aforementioned associations of PADI4 genotype with clinical RA characteristics, possible explanations for the heterogeneity of previous association studies assessing PADI4 in RA may be delineated.

In this study, we tested the hypothesis that PADI4 genotype influences the clinical course of RA directly or dependent on the presence of anti-CCPs. As our study population consisted predominantly of patients with established disease, we primarily used CTI as a marker of disease severity as previously suggested. ${ }^{13}$ CTI represents one major confounder of the erosive joint status itself, as the therapeutic intensity significantly influences joint destruction. ${ }^{20}$ The strong and highly significant association of erosive disease with CTI in univariate and multivariate analyses corroborates the validity of CTI as an indicator of disease severity. Moreover, a highly significant negative association between CTI and DAS28 was observed (table 2). This association is in line with previous reports 
Table 3 Interactive influence of shared epitope and padi4_94C $>$ T genotype on presence of antinuclear antibodies

\begin{tabular}{llllll}
\hline Shared epitope & padi4_94C $>\mathbf{T}$ & $\mathbf{0 R}$ (p value) & $\mathbf{p}^{*}$ & Adjusted OR (p value) & $\mathbf{p}^{*}$ \\
\hline se/se & $\mathrm{C} / \mathrm{C}$ & 1.0 (referent) & $<0.01$ & 1.0 (referent) & 0.006 \\
$\mathrm{se} / \mathrm{se}$ & $\mathrm{T}$ & 3.52 (0.05) & & $6.20(<0.04)$ & \\
$\mathrm{SE}$ & $\mathrm{C} / \mathrm{C}$ & 1.0 (referent) & & 1.0 (referent) & \\
$\mathrm{SE}$ & $\mathrm{T}$ & $0.49(0.07)$ & & $0.36(<0.02)$ & \\
$\mathrm{se} / \mathrm{se}$ & $\mathrm{C} / \mathrm{C}$ & 1.0 (referent) & 0.001 & 1.0 (referent) & 0.0002 \\
$\mathrm{se} / \mathrm{se}$ & $\mathrm{C} / \mathrm{T}$ & $2.83(0.14)$ & & $4.71(0.09)$ & \\
$\mathrm{se} / \mathrm{se}$ & $\mathrm{T} / \mathrm{T}$ & $5.15(<0.03)$ & & $9.58(<0.02)$ & \\
$\mathrm{SE}$ & $\mathrm{C} / \mathrm{C}$ & 1.0 (referent) & & 1.0 (referent) \\
$\mathrm{SE}$ & $\mathrm{C} / \mathrm{T}$ & $0.62(0.25)$ & & $0.50(0.13)$ & \\
$\mathrm{SE}$ & $\mathrm{T} / \mathrm{T}$ & $0.27(<0.02)$ & & $0.16(0.004)$ & \\
\hline
\end{tabular}

Odds ratios (ORs) and $\mathrm{p}$ values of univariate and multivariate analyses (adjusted for sex, antibody to cyclic citrullinated peptide, rheumatoid factor, disease duration, disease activity score 28, cumulative therapy intensity) are given. se/se, shared epitope negative; $\mathrm{SE}$, shared epitope positive.

${ }^{*} p$ values for test of homogeneity across SE strata.

describing significantly more pronounced DAS reductions with more intensive treatment strategies. ${ }^{21} 22$ DAS28 reflects current disease activity and the underlying disease biology, but it is also influenced by the therapeutic approaches. The fact that CTI is associated with erosive disease and related to DAS28 underscores the value of this disease activity tool. Considering our primary hypothesis, we revealed a strong modulating effect of padi4 94C > T genotype on the anti-CCP-mediated influence on CTI (table 2). The association of anti-CCPs with CTI was restricted to carriers of padi4_94T. From a different perspective, in anti-CCP-negative patients, there was no significant association of padi4_94C > T genotype with CTI (fig 1B), but, in antiCCP-positive patients, the proportion of padi4 94T carriers increased progressively with increasing CTI categories (trend test, $p=0.004$ ) (fig $1 \mathrm{~A}$ ). When this phenomenon was analysed in relation to padi4_94T copy number, there was an increase in anti-CCP-positive patients with high therapy intensity (CTI-2/3) from $53.5 \%$ for padi4_94C/C (wild-type) to $65.1 \%$ and $81.3 \%$ for the presence of one and two padi4_94T alleles, respectively (trend test, $\mathrm{p}<0.003$ ) (data not shown). The categorisation of CTI, which we defined a priori as a local adaptation of the one described previously, is of course arbitrary. Moreover, this measure of disease severity is difficult to standardise. However, post hoc analyses based on CTI categories, which exactly reflect those previously described, did not substantially alter the results. ${ }^{13}$ A modulating effect of padi4_94C $>\mathrm{T}$ genotype on anti-CCP-mediated severity of disease can be explained in several ways. The stability of mRNA derived from PADI4 susceptibility genotypes is increased, and high concentrations of PADI4 in inflamed synovium are specific to patients with RA. ${ }^{12}{ }^{23}$ Thus, an increased amount of intra-articular immune complexes may increase disease severity in anti-CCP-positive carriers of padi4_94T. Differences in responsiveness to antirheumatic drugs may be another explanation for this finding.

The second major finding of this study is the significant trend towards higher padi4_94T carrier frequency with increasing Steinbrocker score (fig 2 ), although padi4_94C $>$ T itself was not associated with erosive disease defined as Steinbrocker score $\geqslant$ II. Thus, PADI4 genotype was associated with more intense joint destruction corresponding to Steinbrocker scores III and IV. Interestingly, the padi4_94T carrier frequencies of patients with RA with the lowest CTI (CTI-1, 63.0\%) or non-erosive disease (Steinbrocker score $\leqslant \mathrm{I}, 67.6 \%$ ) are nearly exactly the same as in our controls (61.9\%) (figs 1 and 2). This finding may help us to understand discrepant results from different association studies performed on PADI4 genotype and susceptibility to $\mathrm{RA}^{1011}$ because the disease severity of the study population appears to influence significantly the padi4_94C $>$ T genotype distribution. In the present study, padi4 $94 \mathrm{~T}$ carrier status and padi4 94T allele dose were significantly associated with susceptibility to RA when a case-control analysis was performed $(O R=1.38, p=0.02$ and trend test, $p=0.005$, respectively). This association of padi4 94T with RA was restricted to patients with higher CTI (CTI-2/3) or erosive disease (Steinbrocker score $\geqslant I I$ ). Thus, study populations from tertiary care units consisting of patients with RA with longstanding disease and long therapeutic histories could be positively selected for so-called susceptibility genotypes of PADI4.

Anti-CCP presence is a well-established risk factor for erosive disease. $^{24} 25$ The lack of association of anti-CCP presence with erosive disease in our study population needs consideration. The predictive value of anti-CCPs with respect to joint destruction seems to depend on the treatment strategy, as, in a recent study, progressive disease could only be predicted by anti-CCPs in those patients treated with sequential monotherapy. ${ }^{26}$ As a step-up combination therapy approach was predominantly chosen in our patients, the effect of anti-CCPs on joint destruction may have been attenuated. The current data mandate a prospective study, which should not only address the genetic and serological profile but also take advantage of more sensitive methods for evaluating radiological changes.

Finally, the interactive influence of padi4_94C $>\mathrm{T}$ and SE on ANAs should be addressed (table 3). The highly heterogeneous association of padi4_94C > T genotype with ANAs between the two SE strata is an unexpected finding. However, as this phenomenon was found for padi4_94T carrier status as well as in a marked padi4_94C $>\mathrm{T}$ allele-dose-dependent fashion, this finding appears to be conclusive. However, despite the high level of significance for the testing for heterogeneity between the two SE strata, further studies should be carried out to confirm this finding. It could be argued that SE contributes to susceptibility to RA primarily by mediating anti-CCP generation, and that, in SE-negative RA, alternative pathogenetic pathways are involved, which may be promoted by padi4_94T possibly by generating autoantibodies predominantly reactive with nuclear antigens.

Several limitations of our study should be discussed. The main findings are based on retrospective case-only analyses. Thus, biases due to the selection of an appropriate control group can be excluded. ${ }^{27}$ Nevertheless, confounding due to possible selective referral of patients has to be kept in mind. The size of 
the study population does not allow a detailed sub-stratification, which would help us to completely understand the interactive effects of SE and padi4_94C $>$ T on autoantibody profile and the conjoint influence of all three variables on clinical course of RA. Moreover, data on environmental RA risk factors in our study population are missing, which may have helped to elucidate gene-environment interactions.

Nevertheless, the data presented suggest that combined information on PADI4 genotype and anti-CCP status may represent key data for defining signatures of RA subsets with different clinical courses. Moreover, the interactive influence of PADI4 genotype and SE on the generation of differentiated autoantibody profiles may provide further evidence for the existence of different pathogenetic pathways in RA.

Acknowledgements: We gratefully acknowledge the help of Anja Wachtel and Silvia Pade. We thank the HLA/DNA laboratory for excellent technical assistance. This work was supported by the German Federal Ministry of Education and Research (BMBF) through the National Genome Research Network (NGFN-2, Infection \& Inflammation Network SIPAGE, grant 01GS0413), the EU project AutoCure (grant 018661) and the German Science Foundation (DFG, grant HA-2267/2).

Competing interests: None.

Ethics approval: Obtained.

Patient consent: Obtained.

Contributors: BH conceived and designed the study. TH, GRB, KE and BH coordinated sample acquisition and laboratory analyses. TH, TD and BH defined clinical end points, analysed and interpreted the data. BH drafted the manuscript. KE, RG, HK, AS, GRB and TD critically revised the manuscript for important intellectual content. All authors had full access to all data and approved the final version of the manuscript.

\section{REFERENCES}

1. Lee DM, Weinblatt ME. Rheumatoid arthritis. Lancet 2001;358:903-11.

2. Aletaha D, Smolen JS. Challenges of predicting treatment response in patients with rheumatoid arthritis. Nat Clin Pract Rheumatol 2005;1:62-3.

3. Vencovsky J, Huizinga TW. Rheumatoid arthritis: the goal rather than the healthcare provider is key. Lancet 2006;367:450-2.

4. Bukhari M, Lunt M, Harrison BJ, Scott DG, Symmons DP, Silman AJ. Rheumatoid factor is the major predictor of increasing severity of radiographic erosions in rheumatoid arthritis: results from the Norfolk Arthritis Register Study, a large inception cohort. Arthritis Rheum 2002;46:906-12.

5. Cantaert T, De Rycke L, Bongartz T, Matteson EL, Tak PP, Nicholas AP, et al. Citrullinated proteins in rheumatoid arthritis: crucial... but not sufficient! Arthritis Rheum 2006;54:3381-9.

6. Hill JA, Southwood S, Sette A, Jevnikar AM, Bell DA, Cairns E. Cutting edge: the conversion of arginine to citrulline allows for a high-affinity peptide interaction with the rheumatoid arthritis-associated HLA-DRB1 ${ }^{*} 0401 \mathrm{MHC}$ class II molecule. J Immunol 2003;171:538-41.

7. Padyukov L, Silva C, Stolt P, Alfredsson L, Klareskog L. A gene-environment interaction between smoking and shared epitope genes in HLA-DR provides a high risk of seropositive rheumatoid arthritis. Arthritis Rheum 2004;50:3085-92.

8. Klareskog L, Stolt P, Lundberg K, Kallberg H, Bengtsson C, Grunewald J, et al. A new model for an etiology of rheumatoid arthritis: smoking may trigger HLA-DR (shared epitope)-restricted immune reactions to autoantigens modified by citrullination. Arthritis Rheum 2006;54:38-46.

9. Pedersen M, Jacobsen S, Garred P, Madsen HO, Klarlund M, Svejgaard A, et al. Strong combined gene-environment effects in anti-cyclic citrullinated peptide-positive rheumatoid arthritis: A nationwide case-control study in Denmark. Arthritis Rheum 2007; 56:1446-53.

10. Lee YH, Rho YH, Choi SJ, Ji JD, Song GG. PADI4 polymorphisms and rheumatoid arthritis susceptibility: a meta-analysis. Rheumatol Int 2007;27:827-33.

11. Plenge RM, Padyukov L, Remmers EF, Purcell S, Lee AT, Karlson EW, et al. Replication of putative candidate-gene associations with rheumatoid arthritis in $>4,000$ samples from North America and Sweden: association of susceptibility with PTPN22, CTLA4, and PADI4. Am J Hum Genet 2005;77:1044-60.

12. Suzuki A, Yamada R, Chang X, Tokuhiro S, Sawada T, Suzuki M, et al. Functional haplotypes of PADI4, encoding citrullinating enzyme peptidylarginine deiminase 4, are associated with rheumatoid arthritis. Nat Genet 2003;34:395-402.

13. Cabral D, Katz JN, Weinblatt ME, Ting G, Avorn J, Solomon DH. Development and assessment of indicators of rheumatoid arthritis severity: results of a Delphi panel. Arthritis Rheum 2005;53:61-6.

14. Arnett FC, Edworthy SM, Bloch DA, McShane DJ, Fries JF, Cooper NS, et al. The American Rheumatism Association 1987 revised criteria for the classification of rheumatoid arthritis. Arthritis Rheum 1988;31:315-24.

15. Steinbrocker $\mathbf{0}$, Traeger $\mathrm{CH}$, Batterman $\mathrm{RC}$. Therapeutic criteria in rheumatoid arthritis. JAMA 1949;140:659-62.

16. Hoppe B, Tolou F, Dorner T, Kiesewetter H, Salama A. Gene polymorphisms implicated in influencing susceptibility to venous and arterial thromboembolism: frequency distribution in a healthy German population. Thromb Haemost 2006;96:465-70.

17. Hoppe B, Heymann GA, Tolou F, Kiesewetter H, Doerner T, Salama A. High variability of peptidylarginine deiminase 4 (PADI4) in a healthy white population: characterization of six new variants of PADI4 exons 2-4 by a novel haplotype-specific sequencing-based approach. J Mol Med 2004;82:762-7.

18. Hoppe B, Haupl T, Gruber R, Kiesewetter H, Burmester GR, Salama A, et al. Detailed analysis of the variability of peptidylarginine deiminase type 4 in German patients with rheumatoid arthritis: a case-control study. Arthritis Res Ther 2006;8:R34.

19. Harney S, Wordsworth BP. Genetic epidemiology of rheumatoid arthritis. Tissue Antigens 2002;60:465-73.

20. Visser H, le Cessie S, Vos K, Breedveld FC, Hazes JM. How to diagnose rheumatoid arthritis early: a prediction model for persistent (erosive) arthritis. Arthritis Rheum 2002;46:357-65.

21. Capell HA, Madhok R, Porter DR, Munro RA, Mclnnes IB, Hunter JA, et al. Combination therapy with sulfasalazine and methotrexate is more effective than either drug alone in patients with rheumatoid arthritis with a suboptimal response to sulfasalazine: results from the double-blind placebo-controlled MASCOT study. Ann Rheum Dis 2007:66:235-41.

22. Dale J, Alcorn N, Capell H, Madhok R. Combination therapy for rheumatoid arthritis: methotrexate and sulfasalazine together or with other DMARDs. Nat Clin Pract Rheumatol 2007;3:450-8.

23. Chang X, Yamada R, Suzuki A, Sawada T, Yoshino S, Tokuhiro S, et al. Localization of peptidylarginine deiminase 4 (PADI4) and citrullinated protein in synovial tissue of rheumatoid arthritis. Rheumatology (Oxford) 2005;44:40-50.

24. Berglin E, Johansson T, Sundin U, Jidell E, Wadell G, Hallmans G, et al. Radiological outcome in rheumatoid arthritis is predicted by the presence of antibodies against cyclic citrullinated peptide before and at disease onset, and by IgA-RF at disease onset. Ann Rheum Dis 2006;65:453-8.

25. Turesson C, Jacobsson LT, Sturfelt G, Matteson EL, Mathsson L, Ronnelid J. Rheumatoid factor and antibodies to cyclic citrullinated peptides are associated with severe extra-articular manifestations in rheumatoid arthritis. Ann Rheum Dis 2007:66:59-64.

26. de Vries-Bouwstra JK, Goekoop-Ruiterman YP, Verpoort KN, Schreuder GM, Ewals JA, Terwiel JP, et al. Progression of joint damage in early rheumatoid arthritis: association with HLA-DRB1, rheumatoid factor, and anti-citrullinated protein antibodies in relation to different treatment strategies. Arthritis Rheum 2008;58:1293-8.

27. Khoury MJ, Flanders WD. Nontraditional epidemiologic approaches in the analysis of gene-environment interaction: case-control studies with no controls! Am J Epidemiol 1996;144:207-13. 


\section{ARD}

\section{Influence of peptidylarginine deiminase type 4 genotype and shared epitope on clinical characteristics and autoantibody profile of rheumatoid arthritis}

B Hoppe, T Häupl, K Egerer, et al.

Ann Rheum Dis 2009 68: 898-903 originally published online July 16, 2008

doi: 10.1136/ard.2008.091983

Updated information and services can be found at:

http://ard.bmj.com/content/68/6/898.full.html

These include:

References This article cites 27 articles, 5 of which can be accessed free at: http://ard.bmj.com/content/68/6/898.full.html\#ref-list-1

Article cited in:

http://ard.bmj.com/content/68/6/898.full.html\#related-urls

Email alerting Receive free email alerts when new articles cite this article. Sign up in service the box at the top right corner of the online article.

Topic
Collections

Articles on similar topics can be found in the following collections

Connective tissue disease (3178 articles)

Degenerative joint disease (3439 articles)

Immunology (including allergy) (3758 articles)

Musculoskeletal syndromes (3689 articles)

Rheumatoid arthritis (2407 articles)

Notes

To request permissions go to:

http://group.bmj.com/group/rights-licensing/permissions

To order reprints go to:

http://journals.bmj.com/cgi/reprintform

To subscribe to BMJ go to:

http://group.bmj.com/subscribe/ 